\title{
Neuronal induction and regional identity by co-culture of adherent human embryonic stem cells with chicken notochords and somites
}

\author{
HOSSEIN SALEHI',2, KHADIJEH KARBALAIE1, SHAHNAZ RAZAVI2, SOMAIEH TANHAEE', \\ MARZIYH NEMATOLLAHI ${ }^{1}$, MOHSEN SAGHA ${ }^{3}$, MOHAMMAD-HOSSEIN NASR-ESFAHANI*,1 \\ and HOSSEIN BAHARVAND*,4,5

\begin{abstract}
${ }^{1}$ Department of Cell and Molecular Biology, Royan Institute for Animal Biotechnology, Esfahan, Iran, ${ }^{2}$ Department of Anatomical Sciences, School of Medicine, Esfahan University of Medical Sciences, Esfahan, Iran, ${ }^{3}$ Department of Anatomical Sciences, School of Medicine, Ardebil University of Medical Sciences, Ardebil, Iran, Tehran, Iran and ${ }^{5}$ Department of Developmental Biology, University of Science and Culture, ACECR, Tehran, Iran.
\end{abstract} \\ ${ }^{4}$ Department of Stem Cells and Developmental Biology, Royan Institute for Stem Cell Biology and Technology, ACECR,
}

\begin{abstract}
The role of somites and notochords in neuroectoderm differentiation from the embryonic ectoderm and its subsequent patterning into regional compartments along rostrocaudal and dorso-ventral axes, especially in humans, remains elusive. Here, we demonstrate the co-culture effect of somites and notochords isolated from chicken embryos on the neuronal differentiation and regional identity of an adherent culture of human embryonic stem cells (hESCs). Notochord increased the efficiency and speed of neuronal induction, whereas somites had a weak neuronal inducing effect on hESCs. However, a synergistic effect was not observed when notochords and somites were used together. Moreover, in somite and notochord co-culture groups, hESCs-derived neuronal cells expressed HOXB4, OTX2, IRX3 and PAX6, indicative of dorsal hindbrain and ventral anterior identities, respectively. Our results reveal the influence of embryonic notochord and somite co-culture in providing neuronal induction as well as rostrocaudal and dorso-ventral regional identity of hESCs-derived neuronal cells. This study provides a model through which in vivo neuronal induction events may be imitated.
\end{abstract}

KEY WORDS: Chicken, Co-culture, hESC, Neuronal Induction, Notochord, Somite

\section{Introduction}

Neural induction is the process by which signals such as noggin, follistatin, and chordin that originate from surrounding tissues induce the development of the neural fate in the ectoderm (Gaulden and Reiter, 2008; Khokha et al., 2005; Rashbass et al., 1994; Wessely et al., 2004). These molecules inhibit bone morphogenetic protein (BMP) signaling in the ectoderm and proceeds neural induction by default, in the absence of a specific neuronal inducer (Hemmati-Brivanlou., 1997; Levine and Brivanlou, 2007; Wilson and Edlund, 2001). Therefore, in this hypothesis the inductive signals from the notochord, node and somites are suggested to be unnecessary (Hemmati-Brivanlou., 1997; Munoz-
Sanjuan and Brivanlou, 2002). Despite many advocates of this model, the sole role of the default model in zebra fish, chickens, and mice is questionable (Hurtado and De Robertis, 2007; Klingensmith, 1999; Shimizu, 2000; Stern, 2005; Streit, 2000; Streit et al., 1998). In contrast, other reports show that neural differentiation is the result of direct neural induction by neighboring tissues (Hemmati-Brivanlou, 1994; Kuroda et al., 2004; Sasai, 1995; Smith, 1992). Therefore, the role of somites and notochords in the decision of the ectoderm to acquire a neuroepithelial fate

Abbreviations used in this paper: hESC, human embryonic stem cell; N, notochord; S, somite.

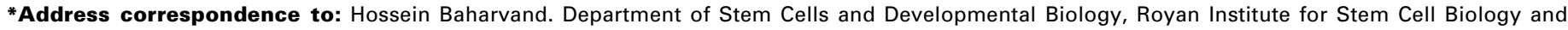
Technology, ACECR, P.O. Box 19395-4644, Tehran, Iran. Fax: +98-21-2231-0406. e-mail: Baharvand@Royanlnstitute.org or

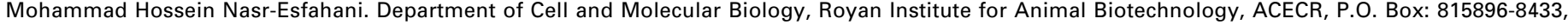
Esfahan, Iran. Fax: +98-311-260-2555. e-mail: mh.nasr-esfahani@Royanlnstitute.org
}

Supplementary Material (two tables) for this paper is available at: http://dx.doi.org/10.1387/ijdb.103185hs

Accepted: 23 September 2010. Final author corrected PDF published online: 15 June 2011.

ISSN: Online 1696-3547, Print 0214-6282

(c) 2011 UBC Press

Printed in Spain 
and its subsequent patterning into regional compartments along the rostro-caudal and dorso-ventral axes, especially in humans, remains elusive. Given the complexity of cellular signaling pathways in vivo, co-cultures are a model to assess differentiation under controlled conditions, with the advantage of being able to replicate some tissue-derived signaling (Anjomshoa et al., 2009;
Sagha et al., 2009). Recently, we have demonstrated that coculturing mice embryonic stem cells (ESCs) with chicken embryonic somites and notochords resulted in neuronal induction and ventral identity of differentiated neurons (Anjomshoa et al., 2009; Sagha et al., 2009). On the other hand, the establishment of human ESCs (hESCs) with self-renewal and pluripotency poten-
A

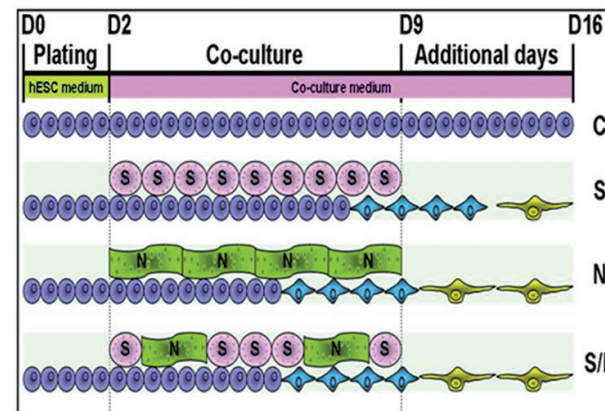

C
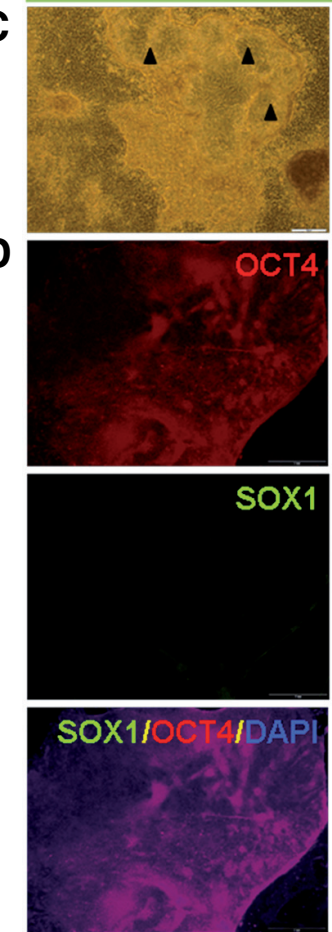

E

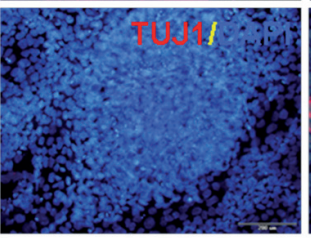

F

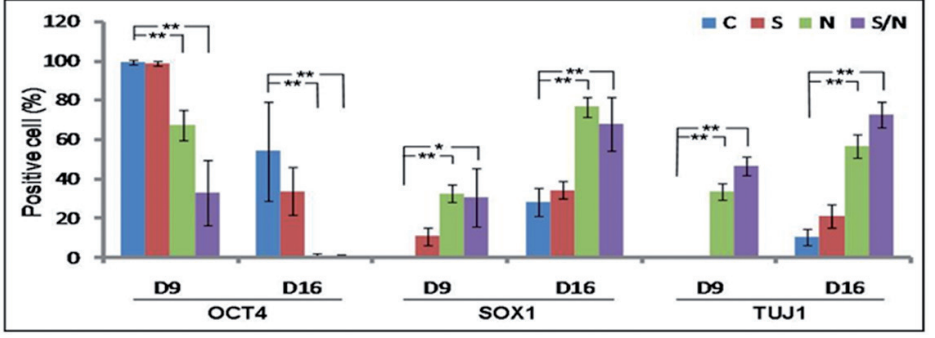

B

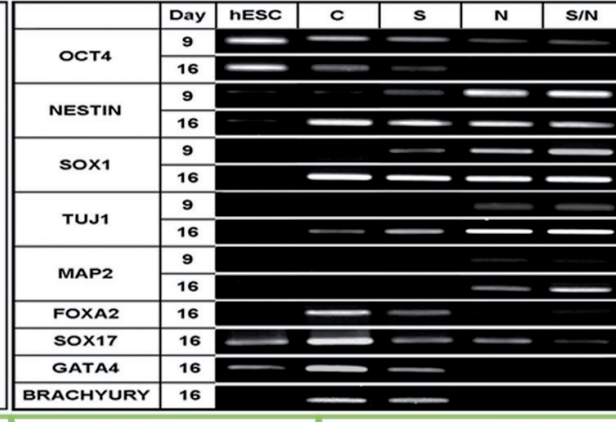
N
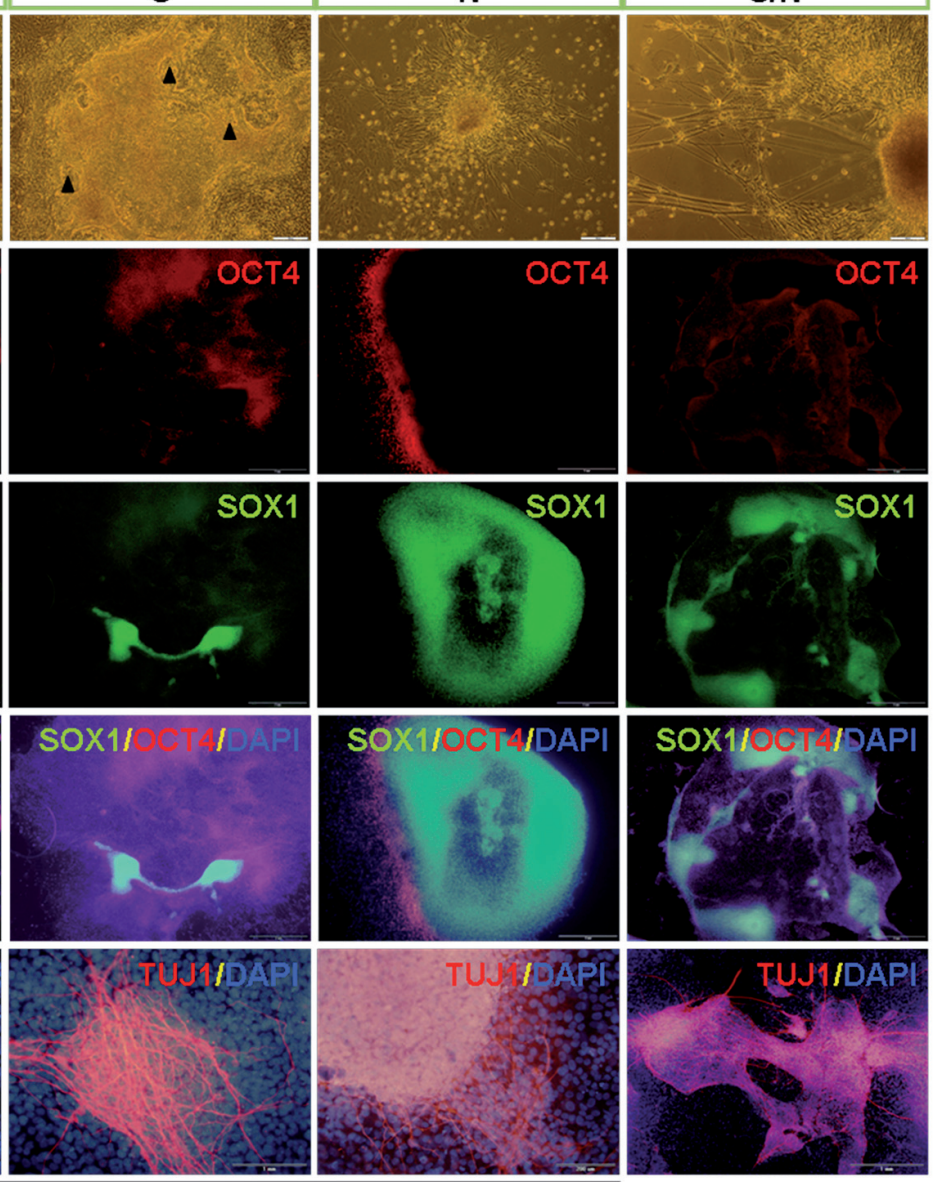

tials provide a most amenable system to investigate these early development events in humans (Pankratz et al., 2007).

Therefore, in this study we sought to examine the influence of chicken embryonic somites and notochords on the neuronal fate as well as the rostro-caudal and dorso-ventral regional identity of adherent cultured hESCs.

\section{Results}

In order to assess the effect of somites (S) and notochords (N) on human neuronal induction, two day old hESCs were cultured either alone (control group, C), in the presence of $\mathrm{S}, \mathrm{N}$, or both $(\mathrm{S} / \mathrm{N})$ which were derived from stages 9-12 chick embryos and encapsulated in alginate beads up day $9(=2+7)$. Beads were subsequently removed from the plates and induced hESCs were allowed to culture in co-culture medium for an additional seven days in vitro (day 16= 2+7+7; Fig. 1A).

hESCs treated with $\mathrm{N}$ or $\mathrm{S} / \mathrm{N}$ at day 16 were negative for endoderm (FOXA2, SOX17) and mesoderm

Fig. 1. Co-culture with notochord (N) and somite/notochord (S/N) accelerated neuronal induction from hESCs. I/lustration protocol of co-culture with hESCS (A). Transcriptional analysis confirms loss of stem marker at day 9 and up-regulation of progenitorand mature neuronalmarkers at day 9 in $N$ and $S / N$ groups, the loss of endodermal markers (FoxA2 and SOX17) by day 16 and the absence of mesodermal markers (GATA4 and BRACHYURY) in both the $N$ and $S / N$ groups (B). Phase contrast images of groups showed cystic formations in the $C$ group (arrow heads), rosette formation in the $S$ group (arrow heads) and mature neuron(s) in the $N$ and S/N groups (C). Neuronal induction from hESCs using coculture led to down-regulation of OCT4 and up-regulation of SOX1 and TUJ1 at day 9, which was more intense in the $N$ and S/N groups (D,E). A quantification of the immune experiment confirmed significant acceleration in loss of pluripotency and expression of neuronal marker when using $N$ and $S / N$ compared to the control (F). Data are shown as mean $\pm S D(n=8$, more than 500 cells were counted in each group, ${ }^{*} p<0.01,{ }^{*} p \leq 0.001$. 
(GATA4, BRACHYURY) markers. However, these markers were expressed in the $C$ and $S$ groups (Fig. 1B). Moreover, the expression of OCT4, a pluripotency marker, was not detected at day 16 in the $\mathrm{N}$ and $\mathrm{S} / \mathrm{N}$ groups. However, NESTIN (a marker of neuronal progenitor cells), SOX1 (a marker of neuronal progenitor cells), TUJ1 (a neuronal marker) and expression of MAP2 (a mature neuron marker) were detected at day 9 (Fig. 1B).

The presence of $\mathrm{N}$ or $\mathrm{N} / \mathrm{S}$ gave rise to neuronal cells with cell body and peripheral extensions after 7 days of co-culture. However, in the $\mathrm{C}$ and $\mathrm{S}$ groups, hESCs showed only an early differentiation with rosette structures, a neuroepithelium marker with radially columnar epithelial cells at the same time (Fig. 1C).

Immunofluorescence staining of differentiated cells demonstrated down-regulation of OCT4 and up-regulation of SOX1 and TUJ1 (Figs. $1 \mathrm{D}$ and E). A quantification of the immune experiment confirmed an accelerated efficient neuralization with $32.6 \pm 4.4 \%$ and $30.5 \pm 14.7 \%$ at day 9 and $76.5 \pm 4.8 \%$ and $67.9 \pm 13.6 \%$ at day 16 SOX1-positive cells and $33.5 \pm 4.2 \%$ and $46.5 \pm 4.6 \%$ at day 9 and $56.6 \pm 5.9 \%$ and $72.5 \pm 6.6 \%$ at day 16 TUJ1-positive cells for $N$ and $\mathrm{S} / \mathrm{N}$ groups, respectively compared to the $\mathrm{C}$ and $\mathrm{S}$ groups $(p<0.001$, Fig. 1F). Staining for OCT4 positivity at day 16 was
$54.2 \pm 25.1 \%$ and $33.7 \pm 12.1 \%$ in the $C$ and $S$ groups compared to negligible OCT4-positive cells in the $\mathrm{N}$ and N/S groups at day 16 $(p \leq 0.001$, Fig. 1F) which showed a higher differentiation of hESCs in the $\mathrm{N}$ and $\mathrm{S} / \mathrm{N}$ groups. Our experiments indicated an increase in neuronal differentiation in the presence of $\mathrm{N}$ only. There was no improvement in the $S$ group when compared to the control group.

To evaluate further the influence of $S, N$, and $S / N$ on the positional identity of neural progenitors, we undertook transcriptional profiling of rostro-caudal markers (OTX2, HOXB4, HOXC5 and HOXC8) and dorso-ventral markers (PAX7, IRX3, PAX6, OLIG2, NKX6.1 and NKX2.2) at day 16. These data indicated that OTX2, a rostral marker, was detectable in all groups. However, HOXB4 was only detected in the $\mathrm{C}$ and $\mathrm{S}$ groups and HOXC5 (a cervical spinal cord marker) and HOXC8 (a thoracic spinal cord marker) were not detected in all groups (Fig. 2A). The expression of OTX2 and HOXB4 was confirmed in all groups by immunofluorescence staining (Fig. 2D) and their quantification revealed higher OTX2/TUJ1 double positive cells in $\mathrm{N}$ and $\mathrm{S} / \mathrm{N}$ groups in comparison with the $C$ and $S$ groups ( $<<0.001$; Fig. 2D). It was interesting to note that $S$ induced more expression of HOXB4/ TUJ1 double positive cells in comparison with other groups.
Fig. 2. Influence of somite (S) and N (notochord) on neural progenitors regional identity. $R T-P C R$ analysis of rostro-cau$\mathrm{dal}$ and dorso-ventral axes' genes revealed OTX2 expression in all groups, HOXB4 in the $S$ group, $P A X 7$ in the $C$ and $S$ groups, and ventral markers, IRX3 and $P A X 6$, in the $N$ and $S /$ $N$ groups $(\mathbf{A}, \mathbf{B})$. Immunostaining for OTX2 in the $C$ group, HOXB4 and PAX7 in the $S$ group, and PAX6 in the S/N group confirmed the RT-PCR results (C). A quantification of the immune experiment showed significant expression of the rostral marker, OTX2, in the $N$ and $S$ / $N$ groups, and hindbrain marker, HOXB4, in the $S$ group in relation to TUJ1 positive cells when compared with the $C$ group $(n=$ 8, more than 500 cells were counted in each group, ${ }^{*} p \leq 0.001$ (D).
A

B

\begin{tabular}{|c|c|c|c|c|c|c|}
\hline D-V aXis & HE & C & S & N & S/N & hESC \\
\hline PAX7 & & & & \\
\hline IRX3 & & & & & \\
\hline PAX6 & & & & \\
\hline OLIG2 & & & \\
\hline NKX6.1 & & & \\
\hline NKX2.2 & & & & \\
\hline
\end{tabular}

C
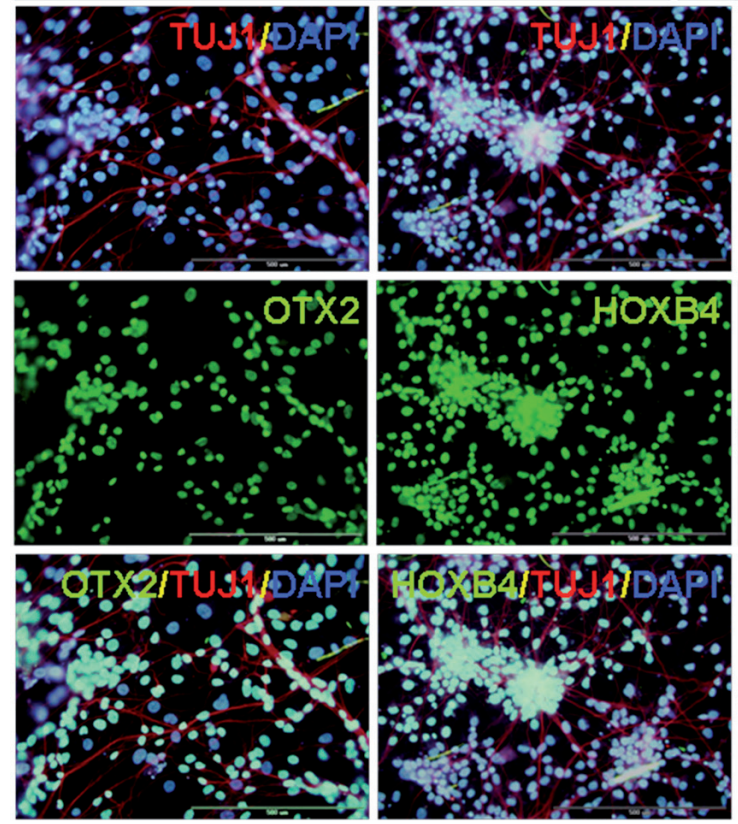

D
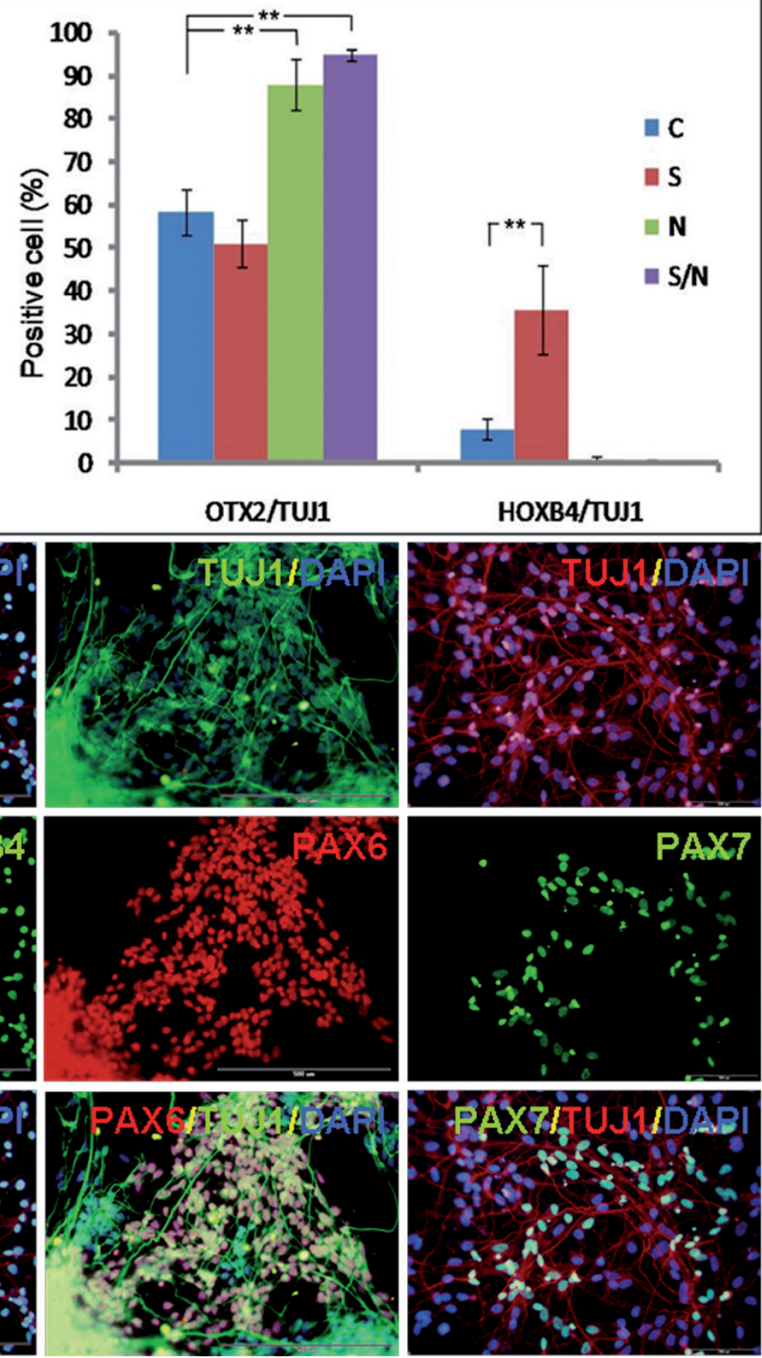
Therefore, it seems that $\mathrm{S}$ and $\mathrm{N}$ make hindbrain and anterior identities for neuronal cells, respectively. Assessment of dorsoventral axis markers using RT-PCR revealed that the $N$ and $S / N$ groups induced the expression of ventral markers IRX3 and PAX6, but not other related ventral markers (OLIG2, NKX6.1 and NKX2.2; Fig. 2B). In contrast, the dorsal marker PAX7 was expressed in both the $S$ and $C$ groups (Fig. 2B). The expression of PAX7 and PAX6 was also detected at the protein level by immunofluorescence staining in the $\mathrm{S}$ and $\mathrm{S} / \mathrm{N}$ groups, respectively (Fig. 2C).

\section{Discussion}

The current study examined the co-culture effect of encapsulated chicken embryonic notochords and somites on neurogenesis as well as rostro-caudal and dorso-ventral regional identity of adherent hESCs. Microencapsulation of somites and notochords into alginate were performed to generate a co-culture system which has been shown to be a good approach to study the interaction between different tissues (Sugie et al., 2005). In this way, somites and notochords were kept separated from hESCs and also allowed the molecules produced by the encapsulated cells to diffuse out into the environment (Erstesvag and Valla, 1998; Smidsrod and Skjak-Braek, 1990).

Our co-culture system with $S$ gave rise to a weak neuronal differentiation as indicated by expression of SOX1 and TUJ1. We previously showed that chicken somites induced rosette structures and weakly enhanced neuronal differentiation from mice ESCs (Sagha et al., 2009) which was in accordance with the"co-culture of somites and ectoderm in Xenopus (Jones and Woodland, 1989). On the other hand, in the $S$ co-culture group, hESC-derived neuronal cells showed HOXB4 and PAX7 expression and dorsal hindbrain identity which was in accordance with previous in vivo reports (Chapman, 2004; Gould et al., 1998; Itasaki et al., 1996; Wilson, 2005). Similar expression of HOXB4 and PAX7 was reported in mice ESC-derived neuronal cells following co-culture with chicken somites (Sagha et al., 2009). However, such fate was not observed in the S/N group's neuronal cells which possibly suggested that the notochord has an inhibitory effect on expression of HOXB4 and PAX7 by somites. The mechanism of somites on neuronal differentiation and possibly caudalization is not clear, however there are several reports indicating that somites secret RA and BMPs antagonists (Deschamps and van Nes, 2005, Diez del Corral and Storey, 2004; Dupe and Lumsden, 2001; Gould et al., 1998; Itasaki et al., 1996; Lewis, 2006; Liem et al., 2000; Maden, 2006). We have previously demonstrated the secretion of retinoids by chicken somites (Sagha et al., 2009), although the levels of all-trans-RA by the somites is low $\left(10^{-9}-10^{-10} \mathrm{M}\right.$ ) (Maden et al., 1998). It seems that this neurogenic effect and hindbrain induction of somites may be a reflection of these signaling molecules however; its mechanism remains to be elucidated.

Moreover, the $\mathrm{N}$ group resulted in earlier and higher expression of neuronal markers SOX1, TUJ1 and MAP2 when compared to the $\mathrm{C}$ and $\mathrm{S}$ groups. Traditionally, the notochord has been believed to be involved in neuronal induction (Harland, 2000; Le Douarin, 2001) while our previous research showed that only the $\mathrm{N}$ group did not induce neuronal differentiation of mice ESC-derived embryoid bodies (EBs) (Anjomshoa et al., 2009). This discrepancy is likely related to the adherent culture implemented in this study instead of a suspension culture by EB formation which prevent the formation of neurectoderm by endogenous Wnt signals (ten Berge et al., 2008 ) or presence of fetal calf serum $(5 \%)$ which contained BMPs or species difference.

The neural inductive role for notochord is not far from expectation, since notochord secrets Shh and BMPs antagonists such as noggin, chordin, follistatin, and flik in the chicken among other vertebrate species (Rolf W. Stottmann, 2006) which have always been involved in neural induction in vivo and in vitro. Moreover, hESC-derived neuronal cells in the $\mathrm{N}$ group had a ventral anterior identity with OTX2, IRX3 and PAX6 expression, which suggests that the $\mathrm{N}$ influences neuronal specification in both the rostrocaudal and dorso-ventral axes. It has been reported that the competent ectoderm of Xenopus embryos (stage 9, late blastula) when wrapped around the anterior notochord of stage $12.5 \mathrm{ex}-$ pressed higher En2, an early anterior neuroectoderm marker, like OTX2 that expresses in this domain compared to the ectoderm which wrapped posterior notochord (Brivanlou and Harland, 1989; Hemmati-Brivanlou et al., 1990). The creation of distinct classes of neurons within the dorso-ventral axis of the developing neuronal tube depends on differential exposure to BMP, Shh and RA from surrounding tissues and this exposure must be carried out at an appropriate time and duration (Ericson, 2001; Jessell, 2000). The reason for the lack of other specific gene expressions may arise from limited co-culture time and the lack of a suitable time window for the neuronal regional identity effect of secreted molecules during co-culture with hESCs or other unknown mechanisms by which these effects are induced.

In conclusion, the results of the present study suggest that the $\mathrm{N}$ group has a strong neurogenic effect on adherent hESCs. In addition, $S$ induces hindbrain identity in the hESC-derived neuronal cells while the $\mathrm{N}$ group maintained their anterior identity of hESC-derived neuronal cells. The mechanisms by which these effects are induced remain to be elucidated.

\section{Materials and Methods}

Preparation of encapsulated alginate bead somites and notochords Chick eggs were provided from commercial sources and incubated in a humidified atmosphere at $38^{\circ} \mathrm{C}$. Embryos of Hamburger and Hamilton stages 9-12 were used for our experiments (Fig. 1A). Chick embryos were isolated from the yolk surface and transferred into Leibovitz's (L15) medium (Invitrogen, 41300-021). Then, embryos were placed in new L15 medium that contained dispase (1 mg/ml, Invitrogen, 17105-041) for 3$5 \mathrm{~min}$ with the purpose of slackening the chick embryo tissues. The enzyme was removed and embryos were washed with L15 medium supplemented with $5 \%$ fetal calf serum (FCS, Invitrogen, 16141-079) for $15 \mathrm{~min}$. Subsequently, embryos were transferred into the clod L15 medium without FCS. Somites and notochords were subsequently isolated from embryos under a dissecting microscope and transferred to coculturing medium. Eventually, 192 somites and 80 notochord pieces (12 somites and 5 notochords/colony) were encapsulated into alginate beads ( 8 beads) for $16 \mathrm{hESCs}$ colonies in 24 wells (replicate $\geq 12$ ). Alginate beads were prepared according to previous references (Anjomshoa et al., 2009; Sagha et al., 2009).

\section{Culturing hESCs}

The feeder free hESC line, Royan H5 (Baharvand et al., 2006) at passages 50-70 was used for these experiments. For hESC maintenance, differentiated cells were removed by gently pipetting. After collagenase IV (1 mg/ml, Invitrogen, 17104-019) treatment the colonies were 
mechanically dissected into small pieces and replated on Matrigel-coated dishes with hESC medium containing DMEM/F12 medium (Invitrogen, 21331-020) supplemented with $20 \%$ knock-out serum replacement (KOSR, Invitrogen, 10828-028), 2 mM L-glutamine (L-glu, Invitrogen, 25030024), $0.1 \mathrm{mM} \beta$-mercaptoethanol (BME, Sigma-Aldrich, M7522), $1 \%$ nonessential amino acids (NEAAs, Invitrogen. 11140-035), 100 units $/ \mathrm{ml}$ penicillin and $100 \mu \mathrm{g} / \mathrm{ml}$ streptomycin (pen/strep, Invitrogen, 15070-063), $1 \%$ insulin/transferring/sodium selenite (ITS, Invitrogen, 41400-045) and $100 \mathrm{ng} / \mathrm{ml}$ basic-fibroblast growth factor (bFGF, Royan Institute). The medium was changed daily. Cells were cultured in $5 \% \mathrm{CO}_{2}$ at $95 \%$ humidity and were further passaged on a weekly basis.

\section{Co-culture with somites and notochords}

hESC colonies, two days after plating in hESC medium on Matrigel, were co-cultured by somites, notochords, and/or both in co-culture medium that included DMEM/F12 supplemented with 5\% KOSR, pen/ strep, 1\% NEAAs, $2 \mathrm{mM}$ L-glu, 1\% ITS, $0.1 \mathrm{mM} \mathrm{BME}$, and 2\% B27 (Invitrogen, 17502-044). After seven days, the beads that contained somites and notochords were removed and colonies were allowed to undergo further differentiation for an additional seven days in co-culture medium. Half of the medium was renewed every other day.

\section{Immunoflourescence staining}

Differentiated cells were washed in PBS and fixed with $4 \%$ paraformaldehyde (Sigma-Aldrich, P6148) in phosphate buffered saline (PBS) for 30 min. Fixed cells were washed twice with PBS before staining. Permeabilization was carried out by $0.2 \%$ Triton X-100 in PBS for 1 hour. Primary antibodies were applied in blocking buffer [ $10 \%$ goat serum and $1 \mathrm{mg} / \mathrm{ml}$ bovine serum albumin (BSA, Sigma-Aldrich, A3311) in PBS] for 1 hour at $37^{\circ} \mathrm{C}$ or overnight at room temperature and washed three times in blocking buffer before the addition of a secondary antibody. Secondary antibodies were diluted in blocking buffer and applied to cells for 2 hours at room temperature. After two washes in PBS, 4,6-diamidino-2phenylindole (DAPI, Sigma-Aldrich, D8417) was applied for 3 min for nuclear counterstaining and cells were observed under fluorescence microscope (Olympus, BX51, Japan). Quantification was estimated by the percentage of positive cells in comparison to the total cells as indicated by DAPI in the fields. For negative controls, primary antibodies were omitted and the same staining procedure was followed. Primary and secondary antibodies are presented in Supplementary Table 1.

\section{Reverse transcription-polymerase chain reaction analysis}

Total RNA was extracted from cultured cells using the QIAprep Spin Miniprep kit (QIAGEN, 27106) according to the manufacturer's protocol. Prior to reverse transcription (RT), RNA samples were digested with DNase I (Fermentas, EN0521) to remove contaminating genomic DNA. Standard RT was performed using $2 \mu \mathrm{g}$ total RNA, oligo (dT) 18 and the RevertAidTM H Minus First Strand cDNA Synthesis kit (Fermentas, K1622) according to the manufacturer's instructions. Primer sequences, annealing temperature(s), cycles and the lengths of amplified products are shown in Supplementary Table 2. Amplification conditions were as follows: initial denaturation at $94^{\circ} \mathrm{C}$ for 5 min followed by 35 cycles of denaturation at $94^{\circ} \mathrm{C}$ for $30 \mathrm{sec}$, annealing for $45 \mathrm{sec}$, extension for $45 \mathrm{sec}$ at $72^{\circ} \mathrm{C}$ and a final polymerization at $72^{\circ} \mathrm{C}$ for $10 \mathrm{~min}$. PCRs were performed in triplicate. PCR products were analyzed by gel electrophoresis on 1.7 or $2 \%$ agarose and stained with ethidium bromide $(10 \mu \mathrm{g} / \mathrm{ml})$, visualized and photographed on a UV transilluminator (Uvidoc, UK). The CNS RNA of a 20 week old human embryo was used as a positive control for RT-PCR analysis.

\section{Statistical analyses}

Quantification of immune and PCR experiments was performed based on eight and three replications, respectively. Data of quantification of the immune staining were expressed as mean $\pm S D$ (standard deviation). One-way ANOVA followed by Tukey's post hoc multiple group compari- son test was used to analyze group differences of the data collected from immunofluorescence staining. A difference between groups was considered as statistically significant if $p<0.05$.

\section{Acknowledgements}

This study was funded by a grant provided from Royan Institute and the Iran National Science Foundation.

\section{References}

ANJOMSHOA, M., KARBALAIE, K., MARDANI, M., RAZAVI, S., TANHAEI, S. NASR-ESFAHANI, M.H. and BAHARVAND, H. (2009). Generation of motor neurons by coculture of retinoic acid-pretreated embryonic stem cells with chicken notochords. Stem Cells Dev 18: 259-267.

BAHARVAND, H., ASHTIANI, S.K., TAEE, A., MASSUMI, M., VALOJERDI, M.R. YAZDI, P.E., MORADI, S.Z. and FARROKHI, A. (2006). Generation of new human embryonic stem cell lines with diploid and triploid karyotypes. Dev Growth Differ 48: 117-128.

BRIVANLOU, A.H. and HARLAND, R.M. (1989). Expression of an engrailed-related protein is induced in the anterior neural ectoderm of early Xenopus embryos. Development 106: 611-617.

CHAPMAN, S.C., BROWN, R., LEES, L., SCHOENWOLF, G. C. AND LUMSDEN, A.. (2004). Expression analysis of chick Wnt and frizzled genes and selected inhibitors in early chick patterning. Dev Dyn 229: 668-676.

DESCHAMPS, J. and VAN NES, J. (2005). Developmental regulation of the Hox genes during axial morphogenesis in the mouse. Development 132: 2931-2942.

DIEZ DEL CORRAL, R. and STOREY, K.G. (2004). Opposing FGF and retinoid pathways: a signalling switch that controls differentiation and patterning onset in the extending vertebrate body axis. Bioessays 26: 857-869.

DUPE, V. and LUMSDEN, A. (2001). Hindbrain patterning involves graded responses to retinoic acid signalling. Development 128: 2199-2208.

ERICSON, J.B.J. (2001). Specifi cation of neuronal fates in the ventral neural tube. Curr Opin Neurobiol 11: 43-49.

ERSTESVAG, H. and VALLA, S. (1998). Biosynthesis and applications of alginates. Polym Degrad Stabil 98: 85-91.

GAULDEN, J. and REITER, J.F. (2008). Neur-ons and neur-offs: regulators of neural induction in vertebrate embryos and embryonic stem cells. Hum Mol Genet 17: R60-66

GOULD, A., ITASAKI, N. and KRUMLAUF, R. (1998). Initiation of rhombomeric Hoxb4 expression requires induction by somites and a retinoid pathway. Neuron 21: 39-51.

HARLAND, R. (2000). Neural induction. Curr Opin Genet Dev 10: 357-362.

HEMMATI-BRIVANLOU, A., KELLY, O. G. \& MELTON, D. A. (1994). Follistatin, an antagonist of activin, is expressed in the Spemann organizer and displays direct neuralizing activity. Cell 77: 283-295.

HEMMATI-BRIVANLOU, A., STEWART, R.M. and HARLAND, R.M. (1990). Region-specific neural induction of an engrailed protein by anterior notochord in Xenopus. Science 250: 800-802.

HEMMATI-BRIVANLOU., W.D.A.A. (1997). Neural induction in Xenopus laevis: evidence for the default model. Curr Opin Neurobiol 7: 7-12.

HURTADO, C. and DE ROBERTIS, E.M. (2007). Neural induction in the absence of organizer in salamanders is mediated by MAPK. Dev Biol 307: 282-289.

ITASAKI, N., SHARPE, J., MORRISON, A. and KRUMLAUF, R. (1996). Reprogramming Hox expression in the vertebrate hindbrain: influence of paraxial mesoderm and rhombomere transposition. Neuron 16: 487-500.

JESSELL, T.M. (2000). Neuronal specification in the spinal cord: inductive signals and transcriptional codes. Nat Rev Genet 1: 20-29.

JONES, E.A. and WOODLAND, H.R. (1989). Spatial aspects of neural induction in Xenopus laevis. Development 107: 785-791.

KHOKHA, M.K., YEH, J., GRAMMER, T.C. and HARLAND, R.M. (2005). Depletion of three BMP antagonists from Spemann's organizer leads to a catastrophic loss of dorsal structures. Dev Cell 8: 401-411.

KLINGENSMITH, J., ANG, S. L., BACHILLER, D. \& ROSSANT, J.. (1999). Neural induction and patterning in the mouse in the absence of the node and its 
derivatives. Dev. Biol 15: 535-549.

KURODA, H., WESSELY, O. and DE ROBERTIS, E.M. (2004). Neural induction in Xenopus: requirement for ectodermal and endomesodermal signals via Chordin, Noggin, beta-Catenin, and Cerberus. PLoS Biol 2: E92.

LE DOUARIN, N.M. (2001). Early neurogenesis in Amniote vertebrates. Int J Dev Biol 45: 373-378.

LEVINE, A.J. and BRIVANLOU, A.H. (2007). Proposal of a model of mammalian neural induction. Dev Biol 308: 247-256.

LEWIS, K.E. (2006). How do genes regulate simple behaviours? Understanding how different neurons in the vertebrate spinal cord are genetically specified. Philos Trans R Soc Lond B Biol Sci 361: 45-66.

LIEM, K.F., JR., JESSELL, T.M. and BRISCOE, J. (2000). Regulation of the neural patterning activity of sonic hedgehog by secreted BMP inhibitors expressed by notochord and somites. Development 127: 4855-4866.

MADEN, M. (2006). Retinoids and spinal cord development. J Neurobiol 66: 726738.

MADEN, M., SONNEVELD, E., VAN DER SAAG, P.T. and GALE, E. (1998). The distribution of endogenous retinoic acid in the chick embryo: implications for developmental mechanisms. Development 125: 4133-4144.

MUNOZ-SANJUAN, I. and BRIVANLOU, A.H. (2002). Neural induction, the default model and embryonic stem cells. Nat Rev Neurosci 3: 271-280.

PANKRATZ, M.T., LI, X.J., LAVAUTE, T.M., LYONS, E.A., CHEN, X. and ZHANG, S.C. (2007). Directed neural differentiation of human embryonic stem cells via an obligated primitive anterior stage. Stem Cells 25: 1511-1520.

RASHBASS, P., WILSON, V., ROSEN, B. and BEDDINGTON, R.S. (1994). Alterations in gene expression during mesoderm formation and axial patterning in Brachyury (T) embryos. Int J Dev Biol 38: 35-44.

ROLF W. STOTTMANN, M.B., KAREN MATTA, MURIM CHOI, JOHN KLINGENSMITH. (2006). The BMP antagonist Noggin promotes cranial and spinal neurulation by distinct mechanisms. Dev. Biol. 295: 647-663.

SAGHA, M., KARBALAIE, K., TANHAEE, S., ESFANDIARI, E., SALEHI, H., SADEGHI-ALIABADI, H., RAZAVI, S., NASR-ESFAHANI, M.H. and BAHARVAND, H. (2009). Neural induction in mouse embryonic stem cells by co-culturing with chicken somites. Stem Cells Dev 18: 1351-1360.
SASAI, Y., LU, B.,nSTEINBEISSER, H. \& DE ROBERTIS, E. M.. (1995). Regulation of neural induction by the Chd and Bmp-4 antagonistic patterning signals in Xenopus. Nature 376: 333-336.

SHIMIZU, T.E.A. (2000). Cooperative roles of Bozozok/Dharma and Nodal-related proteins in the formation of the dorsal organizer in zebrafish. Mech. Dev91: 293303.

SMIDSROD, O. and SKJAK-BRAEK, G. (1990). Alginate as immobilization matrix for cells. Trends Biotechnol 8: 71-78.

SMITH, W.C.H., R. M.. (1992). Expression cloning of noggin, a new dorsalizing factor localized to the Spemann organizer in Xenopus embryos. Cell 70: 829-840.

STERN, C.D. (2005). Neural induction: old problem, new findings, yet more questions. Development 132: 2007-2021.

STREIT, A., BERLINER, A. J., PAPNAYOTOU, C., SIRULNIK, A. \& STERN, C. (2000). Initiation of neural induction by FGF signaling before gastrulation Nature 406: 74-78.

STREIT, A., LEE, K.J., WOO, I., ROBERTS, C., JESSELL, T.M. and STERN, C.D. (1998). Chordin regulates primitive streak development and the stability of induced neural cells, but is not sufficient for neural induction in the chick embryo. Development 125: 507-519.

SUGIE, Y., YOSHIKAWA, M., OUJI, Y., SAITO, K., MORIYA, K., ISHIZAKA, S., MATSUURA, T., MARUOKA, S., NAWA, Y. and HARA, Y. (2005). Photoreceptor cells from mouse ES cells by co-culture with chick embryonic retina. Biochem Biophys Res Commun 332: 241-247.

TEN BERGE, D., KOOLE, W., FUERER, C., FISH, M., EROGLU, E. and NUSSE, R. (2008). Wnt signaling mediates self-organization and axis formation in embryoid bodies. Cell Stem Cell 3: 508-518.

WESSELY, O., KIM, J.I., GEISSERT, D., TRAN, U. and DE ROBERTIS, E.M (2004). Analysis of Spemann organizer formation in Xenopus embryos by cDNA macroarrays. Dev Biol 269: 552-566.

WILSON, L., AND MADEN, M. (2005). Mechanisms of dorsoventral patterning in the vertebrate neural tube. Dev. Biol. 282: 1-13.

WILSON, S.I. and EDLUND, T. (2001). Neural induction: toward a unifying mechanism. Nat Neurosci 4 Suppl: 1161-1168. 


\section{Further Related Reading, published previously in the Int. J. Dev. Biol.}

Challenges and strategies for generating therapeutic patient-specific hemangioblasts and hematopoietic stem cells from human pluripotent stem cells

Ann Peters, Paul W. Burridge, Marina V. Pryzhkova, Michal A. Levine,Tea-Soon Park, Christopher Roxbury, Xuan Yuan, Bruno Péault and Elias T. Zambidis Int. J. Dev. Biol. (2010) 54: 965-990

Novel roles for Notch, Wnt and Hedgehog in hematopoesis derived from human pluripotent stem cells

Chantal Cerdan and Mickie Bhatia

Int. J. Dev. Biol. (2010) 54: 955-964

Increased cellular turnover in response to fluoxetine in neuronal precursors derived from human embryonic stem cells

Eun-Ah Chang, Zeki Beyhan, Myung-Sik Yoo, Kannika Siripattarapravat, Tak Ko, Keith J. Lookingland, Burra V. Madhukar and Jose B. Cibelli

Int. J. Dev. Biol. (2010) 54: 707-715

Comparative study of mouse and human feeder cells for human embryonic stem cells Livia Eiselleova, Iveta Peterkova, Jakub Neradil, Iva Slaninova, Ales Hamp and Petr Dvorak Int. J. Dev. Biol. (2008) 52: 353-363

Spa-1 regulates the maintenance and differentiation of human embryonic stem cells

Young-Jin Lee, Hee-Young Nah, Seok-Ho Hong, Ji-Won Lee, Ilkyung Jeon, Jhang Ho Pak, Joo-Ryung Huh, Sung-Hoon Kim, Hee-Dong Chae, Byung-Moon Kang, Chul Geun Kim and Chung-Hoon Kim

Int. J. Dev. Biol. (2008) 52: 43-53

Neural differentiation from human embryonic stem cells in a defined adherent culture condition Hossein Baharvand, Narges-Zare Mehrjardi, Maryam Hatami, Sahar Kiani, Mahendra Rao and Mahdi-Montazer Haghighi Int. J. Dev. Biol. (2007) 51: 371-378

A comparative analysis of Meox1 and Meox2 in the developing somites and limbs of the chick embryo Susan Reijntjes, Sigmar Stricker and Baljinder S. Mankoo Int. J. Dev. Biol. (2007) 51: 753-759

Differentiation of human embryonic stem cells into hepatocytes in 2D and 3D culture systems in vitro Hossein Baharvand, Seyed M. Hashemi, Saeid Kazemi Ashtiani and Ali Farrokhi Int. J. Dev. Biol. (2006) 50: 645-652

Common culture conditions for maintenance and cardiomyocyte differentiation of the human embryonic stem cell lines, BG01 and HUES-7 Chris Denning, Cinzia Allegrucci, Helen Priddle, Maria D. Barbadillo-Muñoz, David Anderson, Tim Self, Nigel M. Smith, C. Tony Parkin and Lorraine E. Young Int. J. Dev. Biol. (2006) 50: 27-37

Fate maps of the primitive streak in chick and quail embryo: ingression timing of progenitor cells of each rostro-caudal axial level of somites. $\mathrm{K}$ Sawada and H Aoyama

Int. J. Dev. Biol. (1999) 43: 809-815

The formation of somite compartments in the avian embryo.

B Brand-Saberi, J Wilting, C Ebensperger and B Christ

Int. J. Dev. Biol. (1996) 40: 411-420

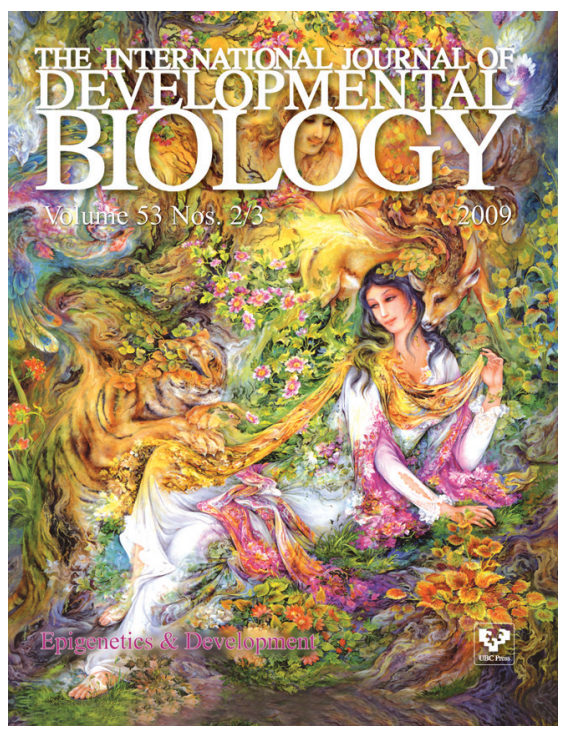

5 yr ISI Impact Factor $(2009)=3.253$

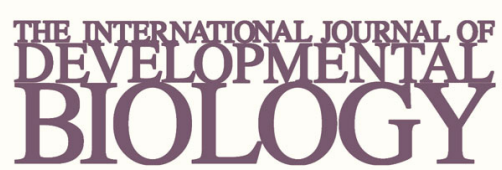

Volume 54 Nos. 6/7
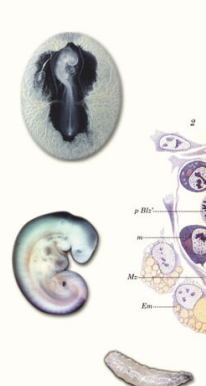

Developmental Hematopoiesis
Special Issue
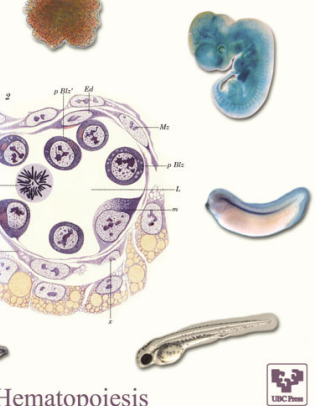

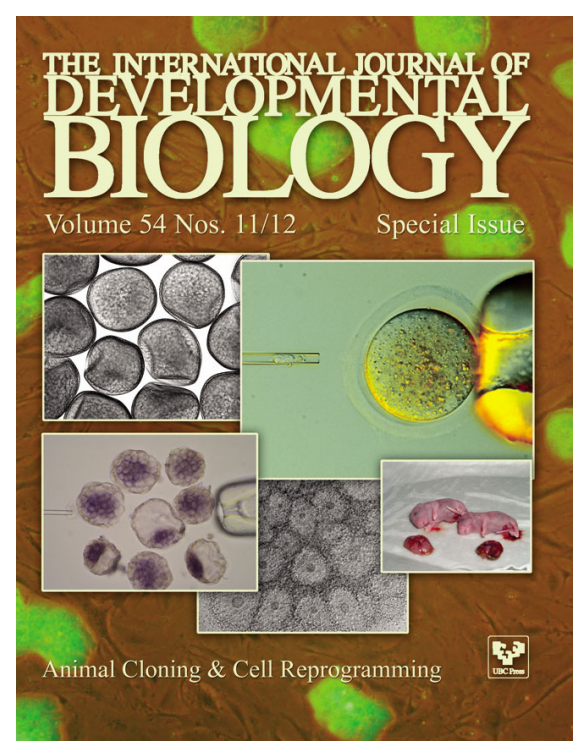

